\title{
The effects of pargyline on overflow of transmitter and uptake of noradrenaline in the cat spleen
}

\author{
A. G. H. BLAKELEY, G. POWIS AND R. J. SUMMERS
}

Department of Pharmacology, The University, Glasgow G12 $8 Q Q$

\section{Summary}

1. Twenty minutes after the addition of pargyline $\left(5 \times 10^{-4} \mathrm{M}\right)$ to blood perfusing the isolated spleen of the cat, the overflow of transmitter resulting from stimulation of the sympathetic nerves increased 2.3-3-fold. Lower doses of pargyline did not significantly affect overflow.

2. Monoamine oxidase activity, measured with either radioactively labelled tyramine or noradrenaline as substrate, was almost completely inhibited by doses of pargyline in the range of $10^{-4} \mathrm{M}$ to $5 \times 10^{-4} \mathrm{M}$. Inhibition of enzyme activity was not correlated with the effect on overflow. Pargyline had only a slight inhibitory effect on catechol- $O$-methyl transferase.

3. Uptake of a $1 \mu \mathrm{g}$ injection (pulse) of labelled noradrenaline, following pargyline $\left(5 \times 10^{-4} \mathrm{M}\right)$, was increased to $199 \cdot 1 \%$ of that found in control experiments.

4. Pargyline significantly reduced the vascular responses to nerve stimulation but had no significant effect on capsular responses.

5. The inhibitor had no effect on resting overflow of labelled noradrenaline from the spleen but doubled the overflow of labelled noradrenaline following nerve stimulation.

6. It is suggested that the effect of pargyline on overflow is due to increased release of transmitter during nerve stimulation.

7. The possible clinical significance of these findings is discussed.

\section{Introduction}

The major route for the inactivation of sympathetic transmitter is at present thought to be uptake into nerves. Some transmitter may be taken up into extraneuronal sites whilst a small fraction is metabolized by enzymes. The remaining transmitter overflows into the venous circulation (Iversen, 1971). The enzymes monoamine oxidase (MAO) and catechol- $O$-methyl transferase (COMT) are responsible for the inactivation of at least part of the transmitter released during field stimulation of the isolated nictitating membrane of the cat (Langer, 1970). However, it is not certain whether enzymes are as important for the inactivation of transmitter released by nerve activity in an intact organ as they clearly are in the saline-bathed, field-stimulated, tissue.

The present study began as an attempt to determine the importance of MAO in the blood perfused cat spleen. The spleen is one of the few organs that provides a measurable overflow of the sympathetic transmitter following nerve stimulation 
(Blakeley, Brown, Dearnaley \& Woods, 1969 ; Brown \& Gillespie, 1957) and it has an enormous capacity for the removal of noradrenaline infused into the arterial blood supply (Gillespie \& Kirpekar, 1965 ; Gillespie, 1966; Blakeley, Brown \& Geffen, 1969 ; Blakeley et al., 1969 ; Gillespie, Hamilton \& Hosie, 1970).

In some early experiments inhibition of MAO by iproniazid produced little effect on transmitter overflow in the cat spleen in situ (Brown \& Gillespie, 1957). The development of the in vitro method of spleen perfusion described by Blakeley et al. (1969) allows a more precise estimate to be made of transmitter overflow. We have therefore made a study of the effects of inhibition of MAO by pargyline on the overflow of transmitter from the cat's spleen. Pargyline was chosen since this drug appears to be one of the few MAO inhibitors which does not release catecholamines or block Uptake ${ }_{1}$ (Iversen, 1967).

\section{Methods}

\section{Overflow of endogenous noradrenaline}

Cat spleens were set up and perfused with blood by the method of Blakeley et al. (1969). Splenic nerves were stimulated with bipolar platinum electrodes. Trains of $200,0.5 \mathrm{~ms}$ impulses at $20 \mathrm{~V}$ were given at a frequency of $10 \mathrm{~Hz}$ every 10 minutes. Blood containing overflowing transmitter was collected for $40 \mathrm{~s}$ from the start of nerve stimulation. In experiments in which the temporal pattern of overflow was studied, blood was collected for a further $40 \mathrm{~s}$ immediately following the first collection period. Perfusion pressure was measured by Ether UP4 and volume by Ether UP1 transducers. Output from the transducers was amplified by SGS 141 T1 operational amplifiers and displayed on an SE 3006 UV Recorder.

\section{Bioassay of noradrenaline}

Blood samples containing transmitter were spun at $3,100 \mathrm{~g}$ for 15 minutes. Plasma was removed from the buffy coat and packed red cells. The plasma samples were assayed for noradrenaline content on the blood pressure of the pithed rat by the method of Gaddum, Peart \& Vogt (1949).

\section{Uptake and release of labelled noradrenaline}

To study the uptake of noradrenaline by the cat spleen, two injections (pulses) of labelled noradrenaline were given into a fine (Portex PP25) polyethylene tube the tip of which terminated at the stainless steel cannula in the splenic artery. The first pulse consisted of $1 \mu \mathrm{g}$ of ${ }^{3} \mathrm{H}-(-)$-noradrenaline base $(5.8 \mathrm{mCi} / \mu \mathrm{M})$ in $0.5 \mathrm{ml}$ ascorbic saline injected over $5 \mathrm{~s}$ and washed in with $0.5 \mathrm{ml} 0.9 \% \mathrm{w} / \mathrm{v} \mathrm{NaCl}$ solution (saline). Venous blood containing ${ }^{3} \mathrm{H}$-noradrenaline that had not been taken up was collected in chilled tubes during the subsequent 3 minutes. The same procedure was repeated for the second $1 \mu \mathrm{g}$ pulse which was ${ }^{14} \mathrm{C}-(-)$-noradrenaline base $(57 \mu \mathrm{Ci} / \mu \mathrm{M})$ given 30 min later.

The pulses of radioactive noradrenaline labelled the neuronal stores of transmitter. Ten minutes after each pulse of labelled noradrenaline the overflow of label following nerve stimulation was tested by stimulating the splenic nerves with 400 impulses at $30 \mathrm{~Hz}$. 
Drugs were added to the perfusion reservoir $3 \mathrm{~min}$ after the first period of nerve stimulation and $20 \mathrm{~min}$ allowed for mixing and for the drug to act.

\section{Radiochemical assay}

Labelled noradrenaline and metabolites overflowing in the venous blood were separated in the following manner. Blood samples were spun as before and aliquots of plasma digested in Soluene (Packard Instrument Co.) prior to determination of radioactivity. Proteins in the remaining plasma were precipitated by adding an equal volume of $20 \%$ conc. $\mathrm{HCl}$ in ethanol, bv standing for $24 \mathrm{~h}$ at $0^{\circ} \mathrm{C}$ and by spinning again. Five $\mu \mathrm{g}$ each of carrier noradrenaline and of its various metabolites were added to the supernatant which was then freeze dried and the residue taken up in a small volume of methanol/water $(1: 1 \mathrm{v} / \mathrm{v})$. The total extract was spotted onto $80 \mu \mathrm{m}$ thick cellulose thin layer chromatographic plates (MN $300 \mathrm{HR}$, Macherey, Nagel \& Co., Durun). The plates were run two dimensionally, firstly in butanol/methanol/1 $\mathrm{N}$ formic acid $(3: 1: 1 \mathrm{v} / \mathrm{v})$ then in chloroform/methanol/1 $\mathrm{N} \mathrm{NH}_{4} \mathrm{OH}(12: 7: 1 \mathrm{v} / \mathrm{v})$ to separate noradrenaline and metabolites (Fleming \& Clark, 1970). The compounds were visualized by spraying with diazotized $p$-nitroaniline and the visible spots scraped into counting vials with $0.5 \mathrm{ml}$ of water and $10 \mathrm{ml}$ Bray's scintillant. All samples were counted differentially for ${ }^{3} \mathrm{H}$, and for ${ }^{14} \mathrm{C}$ in the presence of ${ }^{3} \mathrm{H}$, on a Hewlett-Packard scintillation counter. Corrections for quenching were made.

\section{Determination of enzyme activities}

Spleens were rapidly removed from the organ bath, dissected free of fat and external blood vessels and frozen in liquid $\mathbf{N}_{2}$. The frozen tissue was powdered in a percussion hammer standing in liquid $\mathrm{N}_{2}$. The powder was transferred to a Teflon/glass homogenizer and homogenized in 3 vol of $0.25 \mathrm{M}$ sucrose $/ 0.05 \mathrm{M}$ tris buffer $\mathrm{pH} 7 \cdot 4$.

MAO activity of the homogenate was determined by a modification of the method of Otsuka \& Kobayashi (1964) with ${ }^{14} \mathrm{C}$-tyramine as substrate. Alternatively in some experiments labelled ${ }^{3} \mathrm{H}-(-)$-noradrenaline was used as substrate and the metabolites formed extracted into ethyl acetate. Metabolites formed during $1 \mathrm{~h}$ incubation at $37^{\circ} \mathrm{C}$ were extracted into the organic solvent by shaking for $10 \mathrm{~min}$ and spun at $3,100 \mathrm{~g}$ for $5 \mathrm{~min}$ to separate the layers. An aliquot of the organic layer was placed in a counting vial and $10 \mathrm{ml}$ of butyl PBD scintillant in toluene/2-methoxyethanol (4:1) added. Blank corrections were made. COMT activity of the homogenate was determined by the method of Nikodejevic, Senoh, Daly \& Creveling (1970) using 3.4 dihydroxybenzoic acid as substrate.

\section{Measurement of the blood volume perfusing the isolated spleen of the cat}

The total blood volume in the perfusion apparatus was measured by adding 20 $\mu \mathrm{mol}$ of Evans Blue to the blood in the reservoir. Fifteen min was allowed for thorough mixing then a blood sample was taken, spun and the colour of the plasma after subtraction of plasma blank compared on a Unicam SP 8000 spectrophotometer at $610 \mathrm{~nm}$ to that of known dilutions of Evans Blue. Blood volume could then be read off directly from a graph of intensity against volume.

All results are expressed as mean \pm standard error of mean (S.E.M.). 
Drugs

Evans Blue, Merk, Sharp \& Dohme ; ${ }^{3} \mathrm{H}-(-)$-noradrenaline $(5.8 \mathrm{mCi} / \mu \mathrm{m})$, ${ }^{14} \mathrm{C}$-(-)-noradrenaline $(57 \mu \mathrm{Ci} / \mu \mathrm{m})$, ${ }^{14} \mathrm{C}$-tyramine $(44 \mu \mathrm{Ci} / \mu \mathrm{m})$, S-adenosyl-Lmethionine (methyl $\left.{ }^{14} \mathrm{C}\right)(40 \mu \mathrm{Ci} / \mu \mathrm{m})$, Radiochemical Centre, Amersham; DLnormetanephrine $\mathrm{HCl}, 3$,4-dihydroxymandelic acid, 3,4-dihydroxyphenyl glycol, DL-4-hydroxy 3-methoxy mandelic acid, DL-4-hydroxy 3-methoxyphenyl glycol (piperazine salt), S-adenosyl L-methionine, 3,4-dihydroxybenzoic acid, Sigma Chemical Co.; pargyline hydrochloride, Abbott Laboratories; heparin (mucus), Boots Pure Drug Co. and prostaglandin $\mathrm{E}_{1}$, Dr. John E. Pike, Upjohn, Kalamazoo.

\section{Results}

\section{Overflow of transmitter following nerve stimulation}

(a) Effect of pargyline on overflow of transmitter following nerve stimulation

The experimental procedure was as follows. The total volume of the blood in the circuit perfusing the spleen was calculated by the dye dilution technique. (Evans Blue was found to have no effect on MAO activity or on the overflow of transmitter.) Before the start of the experiment emptying stimuli were given (Blakeley
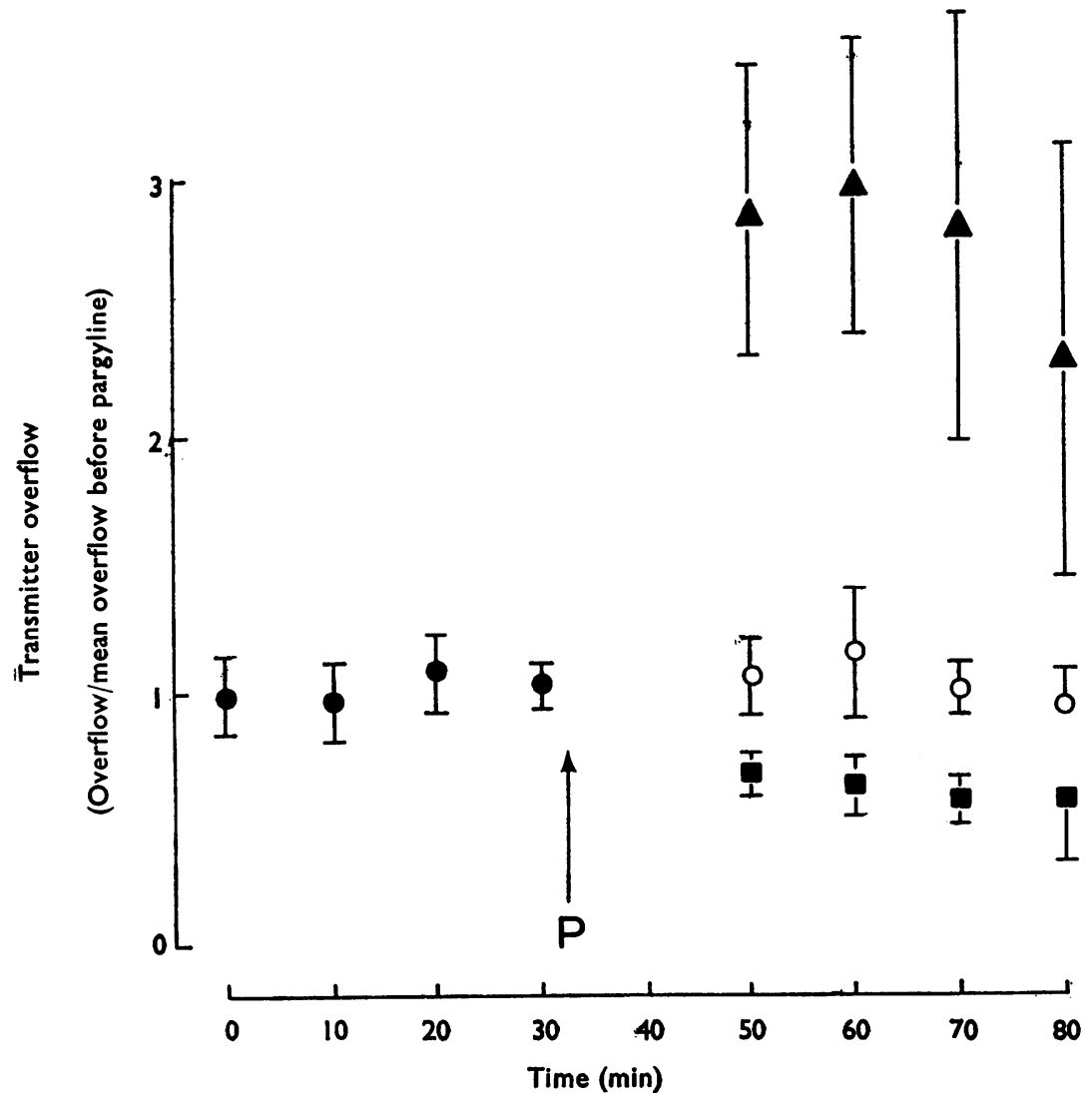

FIG. 1. The effect of pargyline $2 \times 10^{-5} \mathrm{M}(\square) ; 10^{-4} \mathrm{M}(O)$; and $5 \times 10^{-4} \mathrm{M}(\Delta)$, given at the arrow marked $P$, on transmitter overflow from the blood perfused cat spleen. Bars \pm S.EM. 
et al., 1969). This was followed by four periods of stimulation with trains of 200 impulses at $10 \mathrm{~Hz}$ repeated every 10 minutes. Pargyline was added to the blood in the reservoir and given $20 \mathrm{~min}$ to act. The cycle of stimulation and collection was repeated.

Figure 1 shows the effect of pargyline given at three concentrations on transmitter overflow following nerve stimulation. The highest concentrations of inhibitor $\left(5 \times 10^{-4} \mathrm{M}\right)$ significantly $(P<0.001)$ increased the overflow of transmitter $2 \cdot 3-3$-fold following nerve stimulation. The two lower concentrations $\left(10^{-4} \mathrm{M}\right.$ and $\left.2 \times 10^{-5} \mathrm{M}\right)$ had no significant effect.

\section{(b) Pattern of transmitter overflow after pargyline}

Many drugs that affect uptake of noradrenaline such as cocaine (Cripps \& Dearnaley, 1970a) and phenoxybenzamine (Brown \& Gillespie, 1957; Blakeley et al., 1969) both increase and prolong the overflow of transmitter following nerve stimulation. Longer collection periods are therefore necessary for the collection of most of the overflowing transmitter. Accordingly in some experiments an additional sample of venous blood was collected for $40 \mathrm{~s}$ after the collection of the first sample. Pargyline had no significant effect on the pattern of transmitter overflow. In control experiments $30 \cdot 46 \pm 15 \cdot 32 \%(n=5)$ of the total transmitter collected appeared in the second $40 \mathrm{~s}$ collection period whilst in the presence of pargyline $31 \cdot 42 \pm 13 \cdot 26 \%(n=5, P>0.9)$ appeared in the same period.

\section{(c) Responses of the spleen to nerve stimulation}

The spleen responded to nerve stimulation, producing changes in the perfusion pressure (vascular responses), and changes in the spleen volume (capsular responses). Response heights, a measure of the intensity of the response, were measured to the maximum along a perpendicular erected from the mean pre-stimulation perfusion pressure or spleen volume. Response areas, a measure of changes in intensity or duration of response, were measured by planimetry. Vascular and capsular responses were expressed as a fraction of the mean response produced by all periods of stimulation before the addition of pargyline.

The contraction of the splenic capsule was measured only in terms of the height of the volume response since the time-course of the refilling of the spleen is variable. The response to stimulation of the splenic nerve with 200 pulses at $10 \mathrm{~Hz}$ initially increased with each successive train of stimuli irrespective of whether the response was measured as a height or as an area. Each response, both before and after pargyline, was expressed as a fraction of the mean response produced by all periods of stimulation before the addition of pargyline and regression lines were constructed. The regression coefficient ( $\mathrm{r}$ ), the slope of regression of response on time (m) and the intercept of regression of response on time (c) are given in Table 1. A significant correlation was obtained between time and response. After pargyline $5 \times 10^{-4} \mathrm{M}$ had been added to the perfusing blood a significant correlation between response and time was only obtained with pressure height responses and the original upward trend $(\mathrm{m})$ was maintained. However the line was displaced downwards. The intercept on the ordinate (c) of the line before pargyline was 0.94 and after $0 \cdot 60$. This difference was significant at $P<0 \cdot 001$. From this we conclude that pargyline produced a slight maintained inhibition of the vascular response. 
TABLE 1. The effect of pargyline $\left(5 \times 10^{-4} \mathrm{M}\right)$ on the response of the spleen to nerve stimulation $(200$ impulses at $10 \mathrm{~Hz}$ )

\begin{tabular}{|c|c|c|c|c|}
\hline $\begin{array}{l}\text { Response } \\
\text { Control }\end{array}$ & & $\mathbf{r}$ & $\mathrm{m}$ & c \\
\hline Pressure & $\begin{array}{l}\text { Height } \\
\text { Area }\end{array}$ & $\begin{array}{l}0.82 * * * \\
0.83 * * *\end{array}$ & $\begin{array}{l}0.003 \\
0.013\end{array}$ & $\begin{array}{l}0.94 \\
0.79\end{array}$ \\
\hline Volume & Height & $0 \cdot 60 * * *$ & 0.011 & 0.84 \\
\hline After pargylin & e $5 \times 10^{-4} \mathrm{M}$ & & & \\
\hline $\begin{array}{l}\text { Pressure } \\
\text { Volume }\end{array}$ & $\begin{array}{l}\text { Height } \\
\text { Area } \\
\text { Height }\end{array}$ & $\begin{array}{l}0.46^{* *} \\
0.15 \dagger \\
0.23 \dagger\end{array}$ & 0.005 & 0.60 \\
\hline
\end{tabular}

*** $P<0.001 ; * * P<0.05 ; \dagger P>0.3$. $\mathrm{r}=$ regression coefficient. $\mathrm{m}=$ slope of regression of respons on time. $\quad c=$ intercept of regression of response on time.

\section{Uptake and release of labelled noradrenaline}

\section{(a) Uptake of labelled noradrenaline}

Following the injection of $1 \mu \mathrm{g}$ pulse of ${ }^{3} \mathrm{H}-(-)$-noradrenaline into the blood perfusing the spleen, $554 \cdot 3 \pm 51 \cdot 6 \mathrm{ng}(n=12)$ was recovered in a 3 min collection of venous blood. When 3 separate 1 min fractions were collected, less than $3 \%$ of the noradrenaline came over in the 3rd minute. Thirty minutes after the injection of ${ }^{3} \mathrm{H}$-noradrenaline the same dose of ${ }^{14} \mathrm{C}-(-)$-noradrenaline was given in a similar manner ; $668.8 \pm 50.4 \mathrm{ng}(n=6)$ of the ${ }^{14} \mathrm{C}$-labelled noradrenaline appeared in the venous blood. Although the second pulse of noradrenaline did not appear to be taken up as well as the first the difference is not significant $(P>0 \cdot 1)$.

\section{(b) Effect of pargyline on uptake of labelled noradrenaline}

In these experiments pargyline $\left(5 \times 10^{-4} \mathrm{M}\right)$ was added to the blood perfusing the spleen $20 \mathrm{~min}$ before the ${ }^{14} \mathrm{C}$-(-)-noradrenaline. After pargyline the recovery of of ${ }^{14} \mathrm{C}-(-)$-noradrenaline was reduced to $340.9 \pm 98.6 \mathrm{ng}(n=6 ; P<0.02)$. The pargyline-treated spleens took up almost twice as much noradrenaline as the untreated ones.

\section{(c) Release of labelled noradrenaline following nerve stimulation}

Ten minutes after the spleen had taken up the first pulse of noradrenaline $\left({ }^{3} \mathrm{H}\right)$ the splenic nerves were stimulated with 400 impulses at $30 \mathrm{~Hz}$ and venous blood collected for 1 minute. Radioactive noradrenaline was present in this blood $(3 \cdot 45 \pm 1 \cdot 14 \mathrm{ng}, n=12)$ as well as endogenous transmitter. A similar period of stimulation following the second pulse of noradrenaline produced an overflow of ${ }^{14} \mathrm{C}$ label which did not differ significantly from the first (change $+0.21 \pm 0.60 \mathrm{ng}, n=6$ ). However when pargyline was given between the two injections of noradrenaline almost twice as much ${ }^{14} \mathrm{C}$-labelled noradrenaline overflowed after nerve stimulation (change $+3.36 \pm 1.05 \mathrm{ng}, n=6$, significant $P<0.05)$.

\section{Production of noradrenaline metabolites by the spleen}

After injection of labelled noradrenaline some $5 \%$ of the label appeared in the venous blood as metabolites. These were separated from the noradrenaline by thin layer chromatography. The metabolites were grouped according to their route of production. The groups were COMT metabolites (normetanephrine), MAO 
metabolites (3,4-dihydroxymandelic acid ; 3,4-dihydroxyphenylglycol) and metabolites produced by the action of both enzymes, MAO/COMT, (4-hydroxy-3methoxymandelic acid; 4-hydroxy-3-methoxy phenylglycol).

Each experiment was used as its own control. The difference between the amount of metabolites produced after the 1st and 2nd pulse in each experiment was measured and expressed in metabolic overflow. Table 2 shows that the metabolites produced from the first pulse of noradrenaline consist principally of normetanephrine with smaller amounts of MAO and MAO/COMT metabolites. More normetanephrine appeared after the second pulse of noradrenaline than after the first, whereas the amounts of MAO and MAO/COMT metabolites were unchanged. Pargyline $\left(5 \times 10^{-4} \mathrm{M}\right)$ given before the second pulse of noradrenaline significantly reduced the output of MAO metabolites and normetanephrine.

TABLE 2. Overflow of labelled metabolites after injection of $1 \mu \mathrm{g}$ of labelled noradrenaline into the blood perfusing the cat's spleen

Injection

$1 \mu \mathrm{g}{ }^{3} \mathrm{H}-(-)$-noradrenaline

Change in metabolite overflow after $1 \mu \mathrm{g}{ }^{14} \mathrm{C}-(-)$-noradrenaline in the absence of drugs

In the presence of pargyline $5 \times 10^{-4} \mathrm{M}$

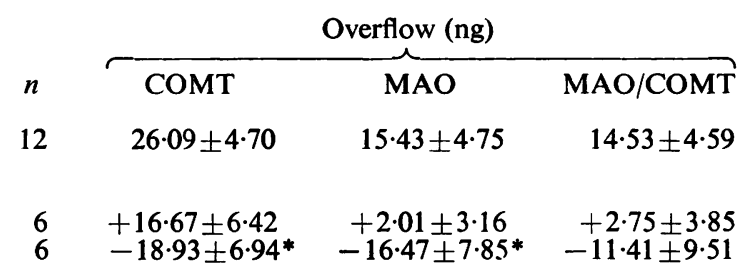

* Significant $P<0.05$.

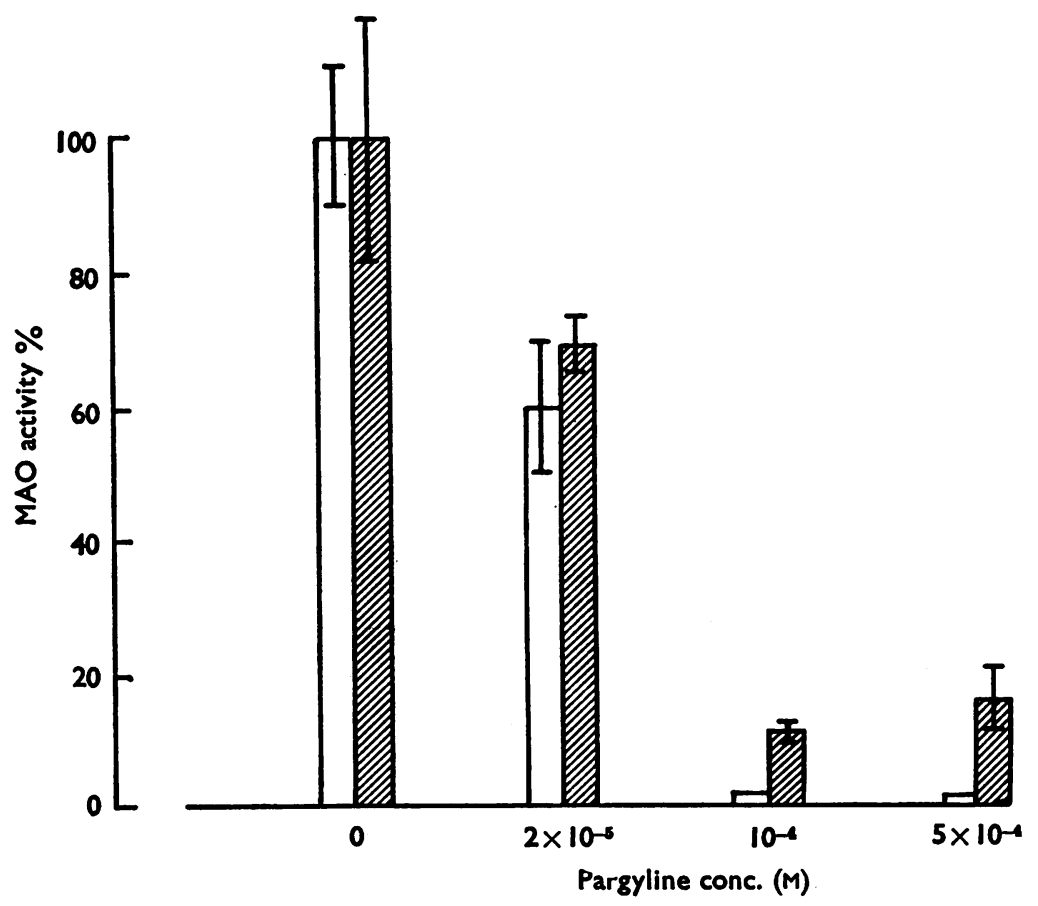

FIG. 2. The effect of pargyline on monoamine oxidase (MAO) activity in homogenates of cat spleens perfused with blood. Open histograms, tyramine used as substrate; cross hatched histograms, noradrenaline used as substrate. Bars \pm S.E.M. 


\section{Monoamine oxidase and catechol-O-methyltransferase activity of spleen homogenates}

MAO activity was measured in spleen homogenates prepared from cats that had received no treatment, or from spleens that had been perfused in the overflow experiments. The perfused spleens were treated with 3 concentrations of pargyline as shown in Figure 2. The two higher concentrations of pargyline almost completely inhibited MAO activity when either tyramine or noradrenaline was used as the substrate.

COMT activity was measured in a spleen homogenate prepared from a cat anaesthetized with halothane. Pargyline-treated $\left(2 \times 10^{-5}, 10^{-4}, 5 \times 10^{-4} \mathrm{M}\right)$ spleen homogenates and substrates were added in that order to ice cold buffer solution. The two lower concentrations of pargyline were found to have no significant effect on COMT activity compared to controls whereas the highest concentration had a slight inhibitory effect ; COMT activity was $87 \cdot 7 \pm 3.48 \%$ of that in controls $(n=3, P<0.05)$. This slight degree of inhibition was considered unlikely to affect the production of normetanephrine.

\section{Discussion}

The MAO inhibitor pargyline at a concentration of $5 \times 10^{-4} \mathrm{M}$ increased the overflow of transmitter following stimulation of the sympathetic nerve supply to the isolated blood-perfused cat spleen. Possible mechanisms that could account for such an effect are inhibition of degradative enzymes, uptake block, receptor block, increased liberation of transmitter or a combination of these effects.

Inhibition of degradative enzymes has been shown to increase the outflow of noradrenaline from the isolated medial muscle of the cat's nictitating membrane following field stimulation (Langer, 1970). In our experiments inhibition of degradative enzymes alone does not appear to be able to explain the observed 2.3-3 fold increase in overflow for several reasons. Measurement of MAO and COMT activities of spleen homogenates after pargyline perfusion showed almost complete inhibition of MAO activity but little effect on COMT. However, almost complete inhibition of MAO was obtained with doses of pargyline of $10^{-4} \mathrm{M}$ and $5 \times 10^{-4} \mathrm{M}$ and yet as shown in Fig. 1 the lower dose had no significant effect on overflow. In addition, in the experiments in which labelled noradrenaline was given, less than $5 \%$ of the label injected appeared as MAO metabolites. If a similar fraction of transmitter is metabolized by MAO after nerve stımulation then inhibition of the enzyme would lead to a similar small increase in the amount of transmitter overflowing-certainly below the observed 2.3-3 fold increase. Since it is also likely that any transmitter escaping normal degradation by MAO would be captured by neuronal and extraneuronal uptake or metabolized by COMT, these studies indicate that the increase in overflow cannot be accounted for simply by MAO inhibition.

The second possibility is that pargyline affects the uptake of transmitter released during nerve stimulation. Inhibitors of both neuronal and extraneuronal uptake have been shown to produce an increased overflow of transmitter following nerve stimulation (Cripps \& Dearnaley, 1970a, b). Since some MAO inhibitors such as tranylcypromine and phenelzine are known to block neuronal uptake (Iversen, 1967) it was thought essential to examine pargyline for such an effect since this could explain the increased overflow. The experiments on uptake show quite 
clearly that pargyline does not block uptake, in fact it apparently potentiates the process. This potentiation of the uptake of labelled noradrenaline occurred in the same experiments in which stimulation of the splenic nerves with 400 impulses at $30 \mathrm{~s}$ resulted in a doubling of overflow of label. The experiments therefore provide evidence that pargyline affects uptake but this cannot explain the increased overflow of transmitter on nerve stimulation. In fact it would tend to reduce overflow. The amount of labelled noradrenaline overflowing after nerve stimulation is too small $(3 \mathrm{ng})$ to enable us to determine whether the increased overflow of label after pargyline is simply due to the increased overflow of transmitter already described, or to what extent an increased labelling of the nerve ending stores of transmitter might be involved.

Although our experiments do not allow us to state the site of the increased uptake, in preliminary experiments the effect was prevented by perfusion of the spleen with blood containing $17 \beta$-oestradiol $(50 \mu \mathrm{g} / \mathrm{ml})$. This steroid has been shown to block Uptake ${ }_{2}$ in the rat heart (Iversen \& Salt, 1970) and the result might indicate that the site of increased uptake is Uptake 2 . However $17 \beta$-oestradiol also inhibits Uptake ${ }_{1}$ to some extent (Salt, 1972) so that the above result cannot be regarded as a clear cut indication that Uptake ${ }_{2}$ is the site of increased uptake.

The third possibility to be considered is receptor block. Cripps \& Dearnaley (1971) have produced evidence indicating that receptors may in some way participate in the uptake of transmitter following nerve stimulation. Enero, Langer, Rothlin \& Stefano (1972) have suggested that $\alpha$-adrenoceptors present on adrenergic nerves might be involved in a negative feedback mechanism regulating transmitter release. In our experiments pargyline did produce a reduction in the vascular response of the spleen to nerve stimulation which could be attributed to $\alpha$-adrenoceptor blockade. A parallel effect on $\alpha$-adrenoceptors on the adrenergic nerves might be expected. Such an effect might increase transmitter overflow. However, the effect on responses of the spleen was small and did not parallel the effect on overflow. The increase in transmitter outflow produced by pargyline in our experiments is not therefore easily attributable to any $\alpha$-adrenoceptor blocking action pargyline may possess.

The final possibility is that pargyline affects the liberation of transmitter. Some drugs are now thought to affect the liberation process. For instance phenoxybenzamine, which also blocks neuronal and extraneuronal uptake sites and $\alpha$ adrenoceptors, appears to enhance the liberation of noradrenaline during nerve stimulation. Evidence for increased liberation has been produced in the saline perfused spleen (de Potter, Chubb, Put \& de Schraepdryver, 1971) rabbit heart (Starke, Montel \& Schumann, 1972) and in isolated guinea-pig atria (AlderGraschinsky, Langer \& Rubio, 1972). (An indirect sympathomimetic effect of pargyline is ruled out since its addition to the system had no effect on resting vascular or capsular tone). Although we have no direct evidence regarding the effect of pargyline on liberation, this is the only mechanism known which would satisfactorily explain the increased overflow.

These effects of pargyline on uptake and liberation of transmitter could explain two of its clinical effects, hypotension and C.N.S. stimulation. The preliminary experiments carried out in this laboratory indicated that the site of the increased uptake after pargyline could be Uptake since the effect is blocked by the Uptake $_{2}$ inhibitor $17 \beta$-oestradiol. In the periphery there is an enormous amount of tissue 
capable of removing noradrenaline by the Uptake Un $_{2}$ process and its potentiation would presumably lead to a decreased effectiveness of transmitter released at sympathetic nerve endings. Hypotension would almost certainly result.

On the other hand extraneuronal uptake in the C.N.S. is probably much less important, therefore the effects of pargyline on release of transmitter may predominate in this area and give rise to the observed C.N.S. stimulation.

The authors wish to thank the Rankin Fund for financial support and Dr. John E. Pike of the Upjohn Co., Kalamazoo for generous gifts of prostaglandin $\mathbf{E}_{1}$.

\section{REFERENCES}

Adler-Graschinsky, E., LANGer, S. Z. \& Rubio, M. C. (1972). Metabolism of norepinephrine released by phenoxybenzamine in isolated guinea pig atria. J. Pharm. exp. Ther., 180, 286-301.

Blakeley, A. G. H., Brown, G. L., Dearnaley, D. P. \& Woods, R. I. (1969). Perfusion of the spleen with blood containing prostaglandin $\mathrm{E}_{1}$ : transmitter liberation and uptake. Proc. $R$. Soc. $B ., 174,281-292$.

Blakeley, A. G. H., Brown, G. L. \& Geffen, L. B. (1969). Uptake and re-use of sympathetic transmitter in the cat's spleen. Proc. R. Soc. B., 174, 51-68.

Brown, G. L. \& Gillespie, J. S. (1957). The output of sympathetic transmitter from the spleen of the cat. J. Physiol., 138, 81-102.

Cripps, H. \& Dearnaley, D. P. (1970a). The effect of cocaine on the noradrenaline overflow from the isolated blood perfused cat spleen. J. Physiol., Lond., 209, 37P-38P.

CRIPPS, H. \& DEARNALEY, D. P. (1970b). The effect of cocaine and normetanephrine on the overflow of noradrenaline from the isolated blood-perfused cat spleen. J. Physiol., Lond., 211, 24-25P.

CRIPPS, H. \& Dearnaley, D. P. (1971). Evidence suggesting uptake of noradrenaline at adrenergic receptors in the isolated blood-perfused cat spleen. J. Physiol., Lond., 216, 55-56P.

Enero A. Maria, Langer, S. Z., Rothlin, R. P. \& Stefano, F. J. E. (1972). Role of the $\alpha$-adrenoreceptor in regulating noradrenaline overflow by nerve stimulation. Br. J. Pharmac., 44, 672-688.

Fleming, R. M. \& ClaRK, W. G. (1970). Quantitative thin-layer chromatographic estimation of labelled dopamine and norepinephrine, their precursors and metabolites. J. Chromatog., 52, 305-312.

Gaddum, J. H., Peart, W. S. \& Vogt, M. (1949). The estimation of adrenaline and allied substances in blood. J. Physiol., Lond., 108, 467-481.

Gillespie, J. S. (1966). Tissue binding of noradrenaline. Proc. R. Soc. B., 166, 1-10.

Gillespie, J. S. \& KirPeKaR, S. M. (1965). The inactivation of infused noradrenaline by the cat spleen. J. Physiol., Lond., 176, 205-227.

Gillespie, J. S., Hamilton, D. N. H. \& Hosie, R. Jeanetre A. (1970). The extraneuronal uptake and localisation of noradrenaline in the cat spleen and the effect on this of some drugs, of cold and of denervation. J. Physiol., Lond., 206, 563-590.

IVERSEN, L. L. (1967). The uptake and storage of noradrenaline in sympathetic nerves. London: Cambridge University Press.

IVERSEN, L. L. (1971). Role of transmitter uptake mechanisms in synaptic neurotransmission. Br. J. Pharmac., 41, 571-591.

IVERSEN, L. L. \& SALT, P. J. (1970). Inhibition of catecholamine Uptake $_{2}$ by steroids in the isolated rat heart. Br. J. Pharmac., 40, 528-530.

LANGER, S. Z. (1970). The metabolism of $\left({ }^{3} \mathrm{H}\right)$ noradrenaline released by electrical stimulation from the isolated nictitating membrane of the cat and from the vas deferens of the rat. J. Physiol., Lond., 208, 515-546.

Nikodejevic, B., Senoh, S., Daly, J. W. \& Creveling, C. R. (1970). Catechol-O-methyltransferase II. A new class of inhibitors of catechol-O-methyltransferase 3.5 dihydroxy 4 methoxybenzoic acid and related compounds. J. Pharm. exp. Ther., 174, 83-93.

Otsuka, S. \& KobaYASHI, Y. (1964). A radioisotope assay for monoamine oxidase determination in human plasma. Biochem. Pharmac., 13, 995-1006.

De Potter, W. P., Chubb, I. W., Put, A. \& De Schaepdryver, A. F. (1971). Facilitation of the release of noradrenaline and dopamine $\beta$ hydroxylase at low stimulation frequencies by $\alpha$ blocking agents. Arch. int. Pharmacodyn., 193, 191-197.

SALT, P. J. (1972). Inhibition of noradrenaline $\mathrm{Uptake}_{2}$ in the isolated rat heart by steroids, clonidine and methoxylated phenylethylamine. Eur. J. Pharmac., 20, 329-340.

Starke, K., Montel, H. \& SchumanN, H. J. (1971). Influence of cocaine and phenoxybenzamine on noradrenaline uptake and release. Naunyn-Schmiedeberg's, Arch. Pharmakol., 270, 210-214.

(Received September 22, 1972) 